\title{
Modelo de gerencia sustentable para fortalecer la competitividad en las empresas del retail "supermercados" de la región de Coquimbo, Chile
}

\author{
Sustainable management model to strengthen competitiveness in "Supermarket" \\ retail companies in the region of Coquimbo, Chile
}

\author{
Ricardo Cabana Villca, Cristhian Javier Pino Castillo* \\ Universidad de La Serena, Chile
}

Recibido el 13 de abril de 2018; aceptado el 9 de mayo de 2019

Disponible en Internet el: 22 de mayo de 2019

\section{Resumen}

En 2014 las empresas del retail en Chile tuvieron ventas equivalentes a US\$ 76000 millones, no obstante, los supermercados solo aportan cerca de un $20 \%$ del total de estas ventas. Además, en la región de Coquimbo el índice de ventas de supermercados es uno de los 4 más bajos a nivel país, es por ello, que se desarrolla el modelo de gerencia sustentable, ya que en contextos tan cambiantes aumentar la competitividad es urgente y estratégico. Esta investigación tiene como objetivo realizar un análisis de los factores que afectan la gerencia sustentable, estos son: factores organizacionales, factores del entorno, compromiso organizacional con la sustentabilidad, liderazgo transaccional y liderazgo transformacional. A su vez, la gerencia sustentable influirá sobre la competitividad, proponiendo de esta forma un modelo con 8 hipótesis. Se toma como población objetivo una fuerza laboral representada por una muestra de 361 trabajadores. Para el contraste del modelo propuesto se emplea el método de ecuaciones estructurales,

\footnotetext{
*Autor para correspondencia.

Correo electrónico cristhianjpc@ gmail.com (C. J. Pino Castillo).

La revisión por pares es responsabilidad de la Universidad Nacional Autónoma de México.

http://dx.doi.org/10.22201/fca.24488410e.2020.2007

0186- 1042/C 2019 Universidad Nacional Autónoma de México, Facultad de Contaduría y Administración. Este es un artículo

Open Access bajo la licencia CC BY-NC-SA (https://creativecommons.org/licenses/by-nc-sa/4.0/)
} 
a través de los Mínimos Cuadrados Parciales (PLS). Se determinó que los constructos anteriormente señalados explican en un $81.6 \%$ la varianza de la gerencia sustentable, y ésta, a su vez, explica en un $68.4 \%$ la varianza de la competitividad, aceptando el total de las hipótesis realizadas.

Código JEL: M14, M14, O15, Q50, O40

Palabras clave: Gerencia sustentable; Factores organizacionales; Liderazgo; Factores del entorno; Competitividad

\begin{abstract}
In 2014, retail companies in Chile had sales equivalent to US \$ 76000 millions, however, supermarkets only contribute about $20 \%$ of the total of these sales. In addition, in the Coquimbo Region, the supermarket sales index is one of the lowest 4 in the country. That is why the sustainable management model is developed, since in such changing contexts increasing competitiveness is urgent and strategic. This research aims to perform an analysis of the factors that affect sustainable management, these are: organizational factors, environmental factors, organizational commitment to sustainability, transactional leadership and transformational leadership. In turn, sustainable management will influence competitiveness, proposing a model with 8 hypotheses. A labor force represented by a sample of 361 workers is taken as the target population. For the contrast of the proposed model, the method of structural equations is used, through those of Partial Least Squares (PLS). It was determined that the previously mentioned constructs explain in $81.6 \%$ the variance of sustainable management, and this, in turn, explains in $68.4 \%$ the variance of competitiveness, accepting the total of the hypotheses made.
\end{abstract}

JEL code: M14, M14, O15, Q50, O40

Keywords: Sustainable management; Organizational factors; Leadership; Environment factors; Competitiveness

\title{
Introducción
}

En un mundo globalizado donde los clientes y el factor ambiental ganan cada vez más importancia, las empresas han tenido que ampliar su visión incluyendo la sustentabilidad dentro de sus modelos de negocio. Los cambios continuos en el entorno de las industrias, están provocando que los clientes tengan más poder en un mundo más interconectado, con empresas que se basan en la creación de valor y el valor compartido, generando el desafío de fortalecer las capacidades para capturar oportunidades desde el caos y las amenazas. Así, la globalización influye en el modo de vivir, en la forma de relacionarse y hacer negocios (Cabana, Cortés, Vega y Cornejo, 2016). 
En este escenario se impulsa además de la rentabilidad, la preocupación por el foco ambiental, es decir, que se transforme ese modelo tradicional a un modelo más ambiental desarrollando tecnologías ambientales, que ayuden a aumentar la productividad haciéndola más limpia, generando campañas verdes, lo que conlleva entonces a los gerentes a trazar nuevos objetivos organizacionales que les permitan una mayor producción con el menor consumo de recursos y reducir los efectos contaminantes (Velásquez, 2017).

El planeta se enfrenta a una crisis económica constante donde el cuidado de los recursos naturales y la materia prima es un imperativo para todas las empresas ya que estos se vuelven cada vez más escasos y, por lo tanto, costosos. Por su parte, la sociedad se encuentra cada día más exigente, solicitando bienes y servicios que provengan de fuentes confiables y que no provoquen un menoscabo al medio ambiente. Es por ello, que el rol del líder centrado en una gerencia sustentable es de gran importancia, ya que así se logran resultados que tengan un punto en común entre lo económico, ambiental y social (de Mello, 2015).

Los líderes de las empresas del retail en Chile deben desarrollar estrategias que incentiven a sus trabajadores a incrementar la productividad con un menor uso de recursos energéticos, reducir los factores contaminantes y contribuir al desarrollo de las comunidades, consiguiendo no solo valor económico, sino que un valor que se distribuya equitativamente con todos sus stakeholders, es decir, ser constantes generadoras de valor compartido.

La mayoría de los grupos de interés, como los clientes, inversionistas, comunidades, trabajadores, entre otros, están conscientes de la importancia de elementos sustentables en su gestión, y que son evaluados al momento de relacionarse con estas organizaciones. Debido a esto, y bajo el concepto de gerencia sustentable, las compañías buscan satisfacer las necesidades de los consumidores de hoy, pero sin comprometer el bienestar de las futuras generaciones. Es decir, hacer negocios, pero sin descuidar los impactos económicos, sociales y ambientales. Hoy la tendencia es que las compañías se identifiquen como empresas sustentables, ya que esto incide directamente en la reputación corporativa de las compañías ante la comunidad (Sánchez, 2011).

En 2014, Chile exportó US\$ 75675 millones, cifra prácticamente equivalente al total de ventas del retail en igual período, la que corresponde a US\$76 000 millones, a su vez, estas ventas son equivalentes al 29\% del PIB de Chile del año 2014 y un 20\% fueron aportadas por los supermercados (Economía y negocios, 2015). Las empresas del retail "supermercados" durante el 2016 fueron creadoras de aproximadamente 190000 empleos en el país (INE, 2016), datos que reflejan la importancia de hacer que estas empresas se vuelvan más sustentables, incrementando así su competitividad, para lograr mayor creación de empleos y mejores resultados que sean favorables al país. 
En la región de Coquimbo actualmente existen 56 supermercados, de los cuales más del $90 \%$ son pertenecientes a las 4 principales retails del país (Walmart, Cencosud, SMU y Falabella retail), los que utilizan como superficie de venta $126222 \mathrm{~m} 2$ y obtienen ingresos equivalentes a los US\$6 795 millones a nivel país (Tabla 1). No obstante, la región presentó en 2016 un índice de ventas de supermercados (ISUP) promedio de 113.93, siendo este uno de los cuatro más bajos a nivel del país, con una variación en 12 meses del 7.7\%. Cabe destacar que el ISUP promedio a nivel país en 2016 fue de 120.22, demostrando que la región se encuentra bajo los estándares que se desean a nivel nacional (INE, 2016).

Tabla 1

Ficha técnica supermercados a nivel país y Regional

\begin{tabular}{lllllll}
\hline Holding & $\begin{array}{l}\text { Ingresos } \\
\text { netos Mi- } \\
11(\mathrm{US} \$)\end{array}$ & $\begin{array}{l}\text { Participación } \\
\text { de mercado } \\
\text { País }\end{array}$ & $\begin{array}{l}\mathrm{N}^{\circ} \text { de tiendas } \\
\text { en el país }\end{array}$ & $\begin{array}{l}\text { Fuerza laboral } \\
\text { en el país }\end{array}$ & $\begin{array}{l}\mathrm{N}^{\circ} \text { tiendas } \\
\text { en la región }\end{array}$ & $\begin{array}{l}\text { Fuerza laboral } \\
\text { en la región }\end{array}$ \\
\hline Walmart & 2791 & $41 \%$ & 363 & 43202 & 13 & 1740 \\
Cencosud & 1911 & $28 \%$ & 245 & 56432 & 12 & 1086 \\
SMU & 1581 & $23.3 \%$ & 510 & 32909 & 24 & 2747 \\
Falabella & 512 & $7.5 \%$ & 61 & 51201 & 2 & 290 \\
\hline Total & 6795 & $99.8 \%$ & 1179 & 183744 & 51 & 5863 \\
\hline
\end{tabular}

Fuente: Elaboración propia en base a memorias anuales1

Por lo anterior, las empresas del retail de Chile y, particularmente, la región de Coquimbo, deben asumir el desafío de aumentar el valor de los productos y servicios comercializados, donde la gerencia sustentable influirá en aumentar el valor agregado de sus bienes y servicios, y simultáneo a esto irá paulatinamente capturando y fidelizando clientes, en un mercado donde el segmento que tiene preferencias pro ambientales crece sostenidamente en Chile y el mundo. Estudios realizados en Chile sobre la sustentabilidad empresarial, dirigido a trabajadores y clientes, reveló que el $91 \%$ de la muestra reconoció que la existencia de políticas de sustentabilidad en su empresa mejoraba su desempeño laboral, además otro 85\% reconoció que su fidelidad con respecto a una empresa aumenta cuando ésta se declara a favor de la sustentabilidad, a su vez el $93 \%$ de ellos manifestó su interés por participar en iniciativas

\footnotetext{
${ }^{1}$ Memorias anuales: Datos Walmart (Memoria anual Walmart, 2016), datos Cencosud (Memoria anual Cencosud, 2016), datos SMU (Memoria anual SMU, 2016), Datos Tottus (Memoria anual Falabella, 2016), $\mathrm{N}^{\circ}$ de tiendas, (INE, 2016).
} 
de las empresas donde trabajan, destinadas a resolver problemas sociales de la comunidad (Fundación PROhumana y PNUD Chile, 2002).

El propósito de este estudio es identificar y analizar las principales variables que influyen en la gerencia sustentable y los resultados que esta provoca en las empresas del retail de la región de Coquimbo, para así contribuir en la instalación de prácticas empresariales sustentables que posibiliten a las empresas chilenas y del mundo a incrementar su competitividad, generando un mayor valor de marca, diferenciación sostenible y sustentable, y un margen de ganancia competitivo que beneficiará a todos los grupos de interés.

\section{Marco teórico}

\section{Gerencia sustentable}

En las organizaciones el papel de líder ha evolucionado, teniendo que adoptar nuevos estilos, entre ellos el que tiene que ver con la sustentabilidad, para hacer más eficiente y competitiva a la organización. La gerencia sustentable es la iniciativa empresarial que implica la adopción de decisiones y prácticas en la vía del cuidado del medio ambiente, el bienestar de los colaboradores y sus familias, y que, al mismo tiempo, impliquen un impacto positivo en el desempeño financiero de una organización (Contreras y Rozo, 2015). Otros autores señalan que la gerencia sustentable, es aquella que incentiva a las organizaciones a trabajar con responsabilidad social empresarial (RSE) y valor compartido, y que busque el establecimiento de objetivos compatibles con el desarrollo social, a través de la preservación de recursos ambientales y culturales para las generaciones futuras, respetando la diversidad y promoviendo la reducción de las desigualdades sociales (Sarmiento, 2010).

La gerencia sustentable es capaz de conseguir resultados que dan competitividad a la organización, y busque en ellos: la sostenibilidad económica, entendida como la capacidad de crecer y desarrollar una actividad económica de manera rentable, y a largo plazo. La sustentabilidad ambiental, referente a la protección efectiva del ambiente físico, a partir del cual se generan los recursos que le permiten a dicha empresa ser sostenible económicamente, crear materias primas para la elaboración y producción de sus bienes o servicios. La sustentabilidad social, encaminada y dirigida a devolver a la sociedad todo aquello que le ha permitido lograr precisamente su crecimiento (Díaz, 2013). Se debe incorporar en las organizaciones y gobiernos el reconocimiento de que existe la necesidad de establecer procesos y estrategias que permitan un equilibrado uso de los recursos naturales disponibles para garantizar un desarrollo actual y futuro. Por lo tanto, es urgente lograr que la dirección estratégica sea 
una práctica laboral cotidiana, entendiéndola como el proceso que permite fundamentar y estimular decisiones para formular e implementar exitosamente las estrategias que le darán a la empresa un valor económico agregado sustentable, centrados en una propuesta de valor que se innova constantemente y un valor económico que se distribuye balanceadamente en cada uno de sus stakeholders (Cabana, Cortés, Vega y Cortés, 2016).

\section{Componentes de la gerencia sustentable}

Ferdig crea un modelo relacional con 8 principios en los que se basa el liderazgo para la gerencia sustentable, los cuales señalan que las organizaciones deben tener en cuenta la sustentabilidad dentro de sus factores organizacionales, es decir, la sustentabilidad debe estar inmersa en el marco estratégico, valores y políticas de la empresa. Además, es importante que las organizaciones comprendan la dinámica del cambio social, aprender, ajustar y expandir la conciencia en su organización teniendo en cuenta los factores del entorno que afectan a la sustentabilidad de la empresa, de esta forma se logra un compromiso organizacional con la sustentabilidad (Ferdig, 2009).

Los principales beneficios económicos que la instauración de la gerencia sustentable causa en cualquier empresa son: aumentar los ingresos, reducir el gasto en insumos, reducir los riesgos estratégicos y operativos, un significativo descenso en el porcentaje de los costos fijos de la empresa, así como un mejor ingreso por los productos y servicios vendidos, una mejora en el clima laboral, un aumento en la productividad (Ibarra, Soto y Delgado, 2015), los que son aspectos claves del liderazgo transaccional con una filosofía de sustentabilidad

Las características de un líder para dar sustentabilidad a la organización deben ser: tener un conocimiento interdisciplinario sistémico, inteligencia emocional y una actitud de cuidado, una orientación a valores que da forma a la cultura organizacional, una fuerte visión para hacer una diferencia, un estilo incluyente que genera confianza, voluntad de innovar y ser radical (Nelson, 2011), es decir, debe tener características de un liderazgo transformacional.

Para una empresa, ser sustentable significa incrementar su competitividad, lo que se logra a través de una gestión sustentable de sus operaciones y de sus relaciones. De lo contrario, corre riesgos cada día más tangibles, de reducir o perder posiciones en algunos mercados y ser excluida de otros (Sánchez, 2011). 


\section{Factores organizacionales}

Los factores del organizacionales potencian y transforman la gerencia sustentable de una obligación estratégica a un compromiso y convicción de la organización con la sustentabilidad, estos son misión, visión, valores y politicas empresariales.

La misión de una organización es la declaración de su propósito como sistema de actividad humana, definiendo el ámbito actual del negocio y de los cambios esperados en el futuro, siendo la brújula que guía la organización (Hernández, Ortega y Garzón, 2011).

La visión estratégica define las aspiraciones de los directivos para la empresa mediante una panorámica del "lugar a donde vamos" y razones convincentes por las cuales es sensato para el negocio (Thompson, Peteraf y Strickland, 2012).

Los valores plantean el marco ético - social dentro del cual la empresa lleva a cabo sus acciones, formando parte de la cultura organizacional y estableciendo los límites en los cuales deben enmarcarse la conducta de los individuos que pertenecen a ella, tanto en lo organizacional como en lo personal (Vidal y Sanchez, 2016).

Las políticas son la filosofía de la gerencia y el pensamiento de altos niveles, refleja el impacto de la organización en la sociedad, además esta política debe articular la estrategia a seguir (Fred, 2017).

Los factores de la cultura organizacional tales como la misión, visión, valores y políticas, sí influyen significativamente en el compromiso organizacional con la sustentabilidad (Carro, Sarmiento y Rosano, 2017).

Hipótesis 1: Los factores organizacionales influyen directa y positivamente sobre el compromiso organizacional con la sustentabilidad.

\section{Factores del entorno}

Tres son los factores del entorno importantes a tener en cuenta en toda organización al momento de generar un compromiso organizacional con la sustentabilidad.

El empoderamiento de las comunidades implica un proceso intencional y continuo, mediante el cual las personas, organizaciones y comunidades carentes de un compartir equitativo de recursos valorados ganan mayor acceso y control sobre esos recursos (Ramos y Maya, 2014).

Por su parte, las políticas de gobierno o públicas, son decisiones y acciones, intencionalmente coherentes, adoptadas por el estado para abordar un problema políticamente definido como colectivo, en un marco institucional específico. Este conjunto de decisiones y acciones 
da lugar a actos formales, con un grado de obligatoriedad variable, tendientes a modificar la conducta de grupos sociales que, se presume, originan el problema colectivo a resolver (Castelao, 2016).

A su vez, las tendencias de la globalización, se refieren a la inclinación por parte del mercado a generar nuevos procesos productivos, formas de venta, etc., dado los avances tecnológicos, y que están principalmente influenciadas por el excesivo crecimiento demográfico y el deterioro del medio ambiente, además de la necesidad de las organizaciones por generar ventajas competitivas que logren satisfacer las necesidades de clientes cada vez más exigentes (Rivas, 2013).

Desde el punto de vista externo, las organizaciones son sistemas abiertos que no pueden sustraerse a las turbulencias del entorno y deben responder adecuadamente a sus presiones dado que la mayor parte de las fuerzas generadoras de cambio se originan en el ámbito externo. En este sentido, la cultura de compromiso organizativo con la sustentabilidad, tiende a generarse cada vez en mayor medida como consecuencia de las tendencias del entorno (Febles y Oreja, 2008). Para las organizaciones estudiar los factores de su entorno es una necesidad, ya que de esta forma se logra estar preparado y tener una estrategia para combatir los cambios que se presentan en las industrias, con ello, se logra generar un mayor compromiso, de forma tal que se logran los objetivos planteados, para dar respuesta a los desafíos del entorno (Ávila, 2017).

Las organizaciones comprometidas con la sustentabilidad, se preocupan por considerar y gestionar factores del entorno, ya que la estimación de escenarios futuros puede ayudar el aprendizaje organizacional en la planeación estratégica y, por ende, en este escenario priorizar el compromiso con la sustentabilidad, con un logro alineado a la estrategia, el conocimiento sobre el entorno exterior y la velocidad de los cambios, y de esta forma se puedan tomar decisiones con más bajo riesgo (Corrêa, 2011).

Hipótesis 2: Los factores del entorno influyen directa y positivamente sobre el compromiso organizacional con la sustentabilidad.

\section{Compromiso organizacional con la sustentabilidad}

Es el compromiso voluntario de empresas con el desarrollo de la sociedad y la preservación del medio ambiente, desde su composición social y un comportamiento responsable hacia las personas y grupos sociales con quienes se interactúa (Gallardo, 2006).

Se plantea que el compromiso organizacional con la sustentabilidad se define como una actitud que expresa una unión psicológica entre el individuo y su organización, es decir, el grado 
de involucramiento y lealtad de los colaboradores con su empresa, el cual se evidencia a través de la identificación de los empleados con los objetivos sustentables y los valores ambientales de la organización, la contribución para el cumplimiento de sus metas y objetivos, y el deseo de ser parte de esta (Araque, Estepa y Uribe, 2017). El compromiso es la habilidad humana, técnica y emocional de personas y grupos de interactuar e influir a través de valores, para la obtención de metas y resultados sostenibles y sustentables, que beneficien y resguarden a las generaciones presentes y futuras. El compromiso con la sustentabilidad va más allá de logros temporales como conseguir buenas puntuaciones, para crear mejoras educativas duraderas y significativas. Sino que este transforma a la organización, dotándola de un compromiso real con los aspectos relacionados a la sustentabilidad (Hargreaves y Fink, 2007).

En la actualidad no sólo existe una mayor consciencia en la sociedad sino un conjunto de normas nacionales e internacionales cuyo compromiso obligatorio o voluntario traen como consecuencia evidentes ventajas y beneficios para unos y otros, es por ello, que las empresas instalan gerencias que buscan comprometerse con la sustentabilidad con el fin de obtener dichos beneficios (Matteo, 2014).

Existe una relación entre la sustentabilidad empresarial y el compromiso de la organización, siendo importante reforzar la idea de que las prácticas de sustentabilidad en las organizaciones responden al contexto de operación de la empresa, a la particularidad de reforzar el compromiso organizacional (Peláez, Solarte y Rodríguez, 2014).

Además, es importante señalar que existe una relación entre el compromiso con la organización y el liderazgo transaccional, de esta forma el cumplimiento de metas y objetivos se logra más eficientemente (Mendoza, García y Xochitototl, 2014 y Chen, Lee y Lee, 2015).

Complementariamente, el liderazgo transformacional se relaciona de forma directa con el compromiso organizacional, ya que los líderes transformacionales comunican una visión clara, inspiran al compromiso organizacional, con esa visión y logran confianza y motivación (Hermosilla, Amutio, de la Costa y Páez, 2016).

Hipótesis 3: El compromiso organizacional con la sustentabilidad influye directa y positivamente sobre el liderazgo transaccional.

Hipótesis 4: El compromiso organizacional con la sustentabilidad influye directa y positivamente sobre el liderazgo transformacional.

Hipótesis 5: El compromiso organizacional con la sustentabilidad influye directa y positivamente sobre la gerencia sustentable. 


\section{Liderazgo transaccional}

El liderazgo transaccional consiste en el intercambio de relaciones entre el líder y los seguidores, basadas en una serie de transacciones que poseen una connotación de reducción de costos y riesgos-incremento de beneficio para la organización y sus colaboradores, menciona que de acuerdo con Bass y Avolio, el líder transaccional se acerca a sus seguidores para negociar lo que se espera de ellos y lo que recibirán a cambio (Silva, Olsen, Pezzi y Sanjurjo, 2016).

Este estilo de liderazgo se basa en la definición del rol del subordinado y las consecuencias positivas o negativas que implica el cumplimiento o no cumplimiento de los objetivos y metas. Se cuadra rígidamente con las metas organizacionales y se preocupa de que los equipos de trabajo bajo su responsabilidad se ocupen meramente de realizar las acciones pertinentes para alcanzar dichas metas (Varela, 2012).

El liderazgo transaccional está relacionado con la gerencia, ya que provoca en sus empleados satisfacción, al obtener un beneficio por el cumplimiento de sus objetivos. El liderazgo transaccional puede llegar a ser una ventaja competitiva para las organizaciones, así para un gerente es importante comprender cómo algunos factores del ambiente organizacional crean un impacto en la satisfacción de los empleados. A partir de ello, un gerente podrá tomar acciones para modificar el comportamiento de sus empleados, mejorar la calidad y productividad del trabajo, favorecer las relaciones interpersonales, lograr la satisfacción laboral que produzca la eficiencia de la organización (Mendoza, García y Xochitototl, 2014).

Hipótesis 6: El liderazgo transaccional influye directa y positivamente sobre la gerencia sustentable.

\section{Liderazgo transformacional}

El liderazgo transformacional es un proceso social que se establece entre el líder y sus seguidores, se caracteriza por ser carismático y por orientarse a conocer ampliamente a cada uno de los miembros de su equipo, de manera que les proporciona retos y oportunidades de desarrollo (Duran y Castañeda, 2015). Apunta a potenciar los deseos de logro y superación de los seguidores, aumentando su confianza y auto-superación, comprometiendo a los trabajadores para el logro de los objetivos mediante los valores que rigen a la organización, permitiendo el bienestar del grupo y el desarrollo de las distintas organizaciones. Lo que se busca es lograr cumplir objetivos tanto personales como institucionales mediante la influencia idealizada (Silva, Olsen, Pezzi y Sanjurjo, 2016). Complementariamente, el líder transforma- 
cional, aboga por que sus colaboradores hagan el trabajo que les corresponde hacer, mas no simplemente por causa de una recompensa al fin del camino, o un sueldo a fin de mes, sino que se enfoca en que los empleados hagan suyas la misión, visión y metas organizacionales, generando un alineamiento estratégico entre las necesidades de las personas y las necesidades organizacionales. En este sentido, el afán por conseguir logros personales como crecimiento, desarrollo, capacidad, felicidad, pueden conseguirse por medio de las tareas desarrolladas dentro de la organización y contribuir en dos frentes a la vez (Varela, 2012).

Las acciones que caracterizan el estilo de liderazgo transformacional promueven un estilo de gerencia más sustentable para las organizaciones (Duran y Castañeda, 2015). En la fase de crear conocimiento mediante un liderazgo con estilo transformacional, influye significativa y positivamente en la generación de nuevas ideas y su socialización, para entregar mayor sustentabilidad a la organización (Delgado, Pedraja y Rodríguez, 2010).

Hipótesis 7: El liderazgo transformacional influye directa y positivamente sobre la gerencia sustentable.

\section{Competitividad}

La competitividad es el conjunto de tres grandes categorías relacionadas con los aspectos económicos, humanos y físicos en el ambiente micro, meso y macro que determinan el nivel de productividad sostenida en el ámbito de las regiones geográficas (García, Lara y de la Parra, 2017).

Cuando se añade sustentabilidad a las organizaciones, se genera un mayor valor de marca, y se pueden esperar beneficios para la empresa, impactando de forma directa en la competitividad de la organización, con factores tales como: generar mayor lealtad de parte de los clientes al aumentar la oferta de valor; permiten ser menos vulnerable a acciones comerciales de la competencia y a las crisis de los mercados; reducen la elasticidad de la demanda ante el aumento de precios como resultado del precio superior que un consumidor está dispuesto a pagar por una marca que le ofrece mayor valor; ayudan a generar confianza y apoyo de los canales de distribución, ya que se ven estimulados al trabajar con marcas de mayor valor, mejoran la comunicación de la empresa con la comunidad (Vera, 2008). También se crea una mayor diferenciación, la estrategia de diferenciación supone una orientación hacia la sustentabilidad, mediante la cual apunta a aumentar la competitividad de la organización, a partir de que la empresa busca la obtención de altos niveles de resultados mediante la creación de productos que sean percibidos como "únicos" y "diferentes" por parte de los competidores. 
La diferenciación también puede generarse a partir de innovaciones en el producto o en el proceso que permitirán a la empresa diferenciarse de sus competidores, generando mayor competitividad dado que se añaden sellos verdes por sus procesos productivos más limpios (Ortega, Villaverde, Moreno y Requena, 2008).

La gerencia sustentable al mejorar el valor de la marca y la diferenciación de los bienes y servicios, ayuda a la gestión del margen de ganancia, este se convierte en un aspecto clave que permite definir los criterios de aumento de productividad, eficacia y eficiencia, esenciales para la competitividad organizacional y, a su vez, la dinámica del subsistema financiero repercute en la realidad competitiva de la organización (Botero, Acevedo y Gómez, 2013).

Incorporar la sustentabilidad en las organizaciones, confirma a las empresas con características que promueven la transparencia y la rendición de cuentas con sus stakeholders, el cumplimiento con los acuerdos establecidos y la resolución de conflictos, atributos que dotan de una mayor competitividad a la organización (Arredondo, de la Garza y Parra, 2014). La gerencia sustentable más que un simple concepto, es un generador de cambio que representa la proactividad, dinamismo, aumento en la competitividad y crecimiento de la empresa, volviéndola sostenible y perdurable en el tiempo. La gerencia sustentable no se limita a la parte legal, ni crear valor para el accionista, sino que busca generar sostenibilidad, crecimiento integral, desarrollo en todos los aspectos creando mayor competitividad para la organización (Díaz, 2013).

Hipótesis 8: La gerencia sustentable influye de forma directa y positivamente a la competitividad.

Considerando las hipótesis planteadas, se establece el modelo causal que busca representar las variables que influyen en la gerencia sustentable y el impacto de ésta en la competitividad de las empresas del retail de la región de Coquimbo-Chile (Figura 1). 


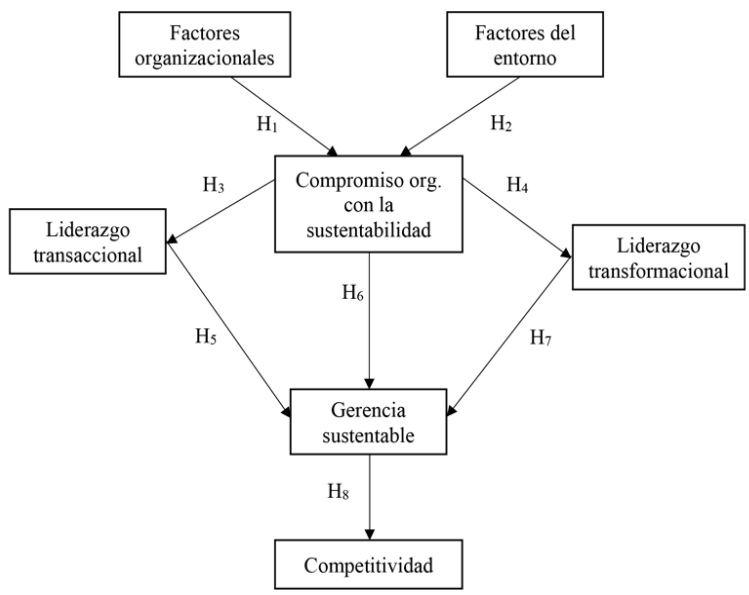

Figura 1. Modelo causal gerencia sustentable

Fuente: Elaboración propia.

\section{Metodología}

El método empleado para recoger la información fue a través de una encuesta estructurada aplicada a trabajadores de las empresas de supermercados de la Región de Coquimbo, fue construido a partir de recopilación de literatura, ajustado al contexto regional, siendo validada por un panel de 5 expertos en el tema. La ficha técnica de la investigación se presenta en la Tabla 2. Dicho instrumento de evaluación se encuentra en el anexo de esta investigación a fin de identificar cada uno de los indicadores. La composición de la muestra se presenta en la tabla 3.

\section{Tabla 2}

Ficha Técnica de la Investigación

\begin{tabular}{ll}
\hline Tipo de muestreo & Muestreo Aleatorio \\
Tamaño de la población & 5863 trabajadores \\
Nivel de confianza & $95 \% ; \mathrm{z}=1,96 ; \mathrm{p}=\mathrm{q}=0,5$ (5\% error y 95\% de confiabilidad). \\
Tamaño muestral & 361 trabajadores \\
Unidad de análisis & Región de Coquimbo, Chile \\
Método de recogida de la información & Cuestionario presencial y online de 67 preguntas \\
Tipo de pregunta encuesta & Politómicas tipo Likert (1 a 5) puntuaciones y de selección. \\
Fecha de realización del trabajo de campo & Entre junio de 2017 y julio de 2017 \\
\hline
\end{tabular}

Fuente: Elaboración propia 
Tabla 3

Integración de la muestra

\begin{tabular}{|c|c|c|c|c|c|}
\hline Variable & Ítem & $\begin{array}{l}\text { Porcentaje en la } \\
\text { Muestra (\%) }\end{array}$ & Variable & Ítem & $\begin{array}{l}\text { Porcentaje en la } \\
\text { Muestra (\%) }\end{array}$ \\
\hline \multirow[t]{4}{*}{ Género } & \multirow[t]{2}{*}{ Hombre } & \multirow[t]{2}{*}{49.6} & \multirow{10}{*}{$\begin{array}{l}\text { Cargo en la } \\
\text { organización }\end{array}$} & Gerencia & 7.8 \\
\hline & & & & Administrador & 24.9 \\
\hline & \multirow[t]{2}{*}{ Mujer } & \multirow[t]{2}{*}{50.4} & & Subadministrador & 13.6 \\
\hline & & & & Supervisor & 14.8 \\
\hline \multirow[t]{2}{*}{ Rango de Edad } & $18-25$ & \multirow[t]{2}{*}{24.3} & & Jefe de área & 12.2 \\
\hline & años & & & & \\
\hline \multirow{6}{*}{ Rango de edad } & $26-35$ & \multirow[t]{2}{*}{39.9} & & \multirow[t]{4}{*}{ Personal de apoyo } & \multirow[t]{4}{*}{26.7} \\
\hline & años & & & & \\
\hline & $35-45$ & \multirow[t]{2}{*}{6.6} & & & \\
\hline & años & & & & \\
\hline & $46-56$ & \multirow[t]{2}{*}{29.1} & \multirow[t]{10}{*}{ Estudios } & Enseñanza Media & 8.6 \\
\hline & años & & & completa & \\
\hline \multirow{8}{*}{$\begin{array}{l}\text { Antigüedad en } \\
\text { la Empresa }\end{array}$} & Menos de & \multirow[t]{2}{*}{20.5} & & Educación técnica & 18.3 \\
\hline & 1 año & & & incompleta & \\
\hline & Entre $1 \mathrm{y}$ & \multirow[t]{2}{*}{24.9} & & Educación universitaria & 28.0 \\
\hline & 5 años & & & incompleta & \\
\hline & Entre 6 y & \multirow[t]{2}{*}{34.9} & & Profesional Titulado & 12.1 \\
\hline & 10 años & & & Técnico & \\
\hline & Entre $11 \mathrm{y}$ & \multirow[t]{2}{*}{19.7} & & Profesional Titulado & 33.0 \\
\hline & 15 años & & & Universitario & \\
\hline
\end{tabular}

Fuente: Elaboración propia.

\section{Análisis de fiabilidad individual de los indicadores}

Con el fin de determinar la fiabilidad individual de los indicadores fue necesario calcular las cargas factoriales, lo que es ejecutable pues el índice de Kaiser-Meyer-Olkin (KMO) fue superior a 0.6 en cada uno de los constructos y la prueba de esfericidad de Bartlett (PEB) fue significativa (p<0.05) (Espinoza, Sanhueza, Ramírez, y Sáez, 2015) (Tabla 4). 
Ricardo Cabana Villca et al. / Contaduría y Administración 65(2) 2020, 1-39

http://dx.doi.org/10.22201/fca.24488410e.2020.2007

Tabla 4

Resultados del análisis estadístico: KMO, PEB y Carga factorial

\begin{tabular}{|c|c|c|c|c|}
\hline Constructo & $\mathrm{KMO}$ & $\begin{array}{l}\text { Significancia de } \\
\text { Bartlett }\end{array}$ & Indicador & Carga Factorial $(\lambda)$ \\
\hline \multirow[t]{12}{*}{ Factores organizacionales } & 0.814 & 0.000 & FO1 & 0.792 \\
\hline & & & $\mathrm{FO} 2$ & 0.904 \\
\hline & & & $\mathrm{FO} 3$ & 0.849 \\
\hline & & & FO4 & 0.842 \\
\hline & & & FO5 & 0.908 \\
\hline & & & FO6 & 0.846 \\
\hline & & & FO7 & 0.828 \\
\hline & & & FO8 & 0.870 \\
\hline & & & FO9 & 0.582 \\
\hline & & & FO10 & 0.838 \\
\hline & & & FO11 & 0.832 \\
\hline & & & FO12 & 0.835 \\
\hline \multirow[t]{9}{*}{ Factores del entorno } & 0.830 & 0.000 & FE1 & 0.777 \\
\hline & & & FE2 & 0.775 \\
\hline & & & FE3 & 0.763 \\
\hline & & & FE4 & 0.727 \\
\hline & & & FE5 & 0.781 \\
\hline & & & FE6 & 0.920 \\
\hline & & & FE7 & 0.913 \\
\hline & & & FE8 & 0.872 \\
\hline & & & FE9 & 0.940 \\
\hline \multirow[t]{5}{*}{ Factores del entorno } & & & FE10 & 0.869 \\
\hline & & & FE11 & 0.927 \\
\hline & & & FE12 & 0.936 \\
\hline & & & FE13 & 0.831 \\
\hline & & & FE14 & 0.844 \\
\hline
\end{tabular}


Ricardo Cabana Villca et al. / Contaduría y Administración 65(2) 2020 1-39

http://dx.doi.org/10.22201/fca.24488410e.2020.2007

\begin{tabular}{|c|c|c|c|c|}
\hline \multirow[t]{5}{*}{ Gerencia sustentable } & \multirow[t]{5}{*}{0.852} & \multirow[t]{5}{*}{0.000} & GS1 & 0.885 \\
\hline & & & GS2 & 0.916 \\
\hline & & & GS3 & 0.971 \\
\hline & & & GS4 & 0.916 \\
\hline & & & GS5 & 0.947 \\
\hline \multirow[t]{8}{*}{ Liderazgo transaccional } & \multirow[t]{8}{*}{0.642} & \multirow[t]{8}{*}{0.000} & LTS1 & 0.821 \\
\hline & & & LTS2 & 0.807 \\
\hline & & & LTS3 & 0.789 \\
\hline & & & LTS4 & 0.824 \\
\hline & & & LTS5 & 0.804 \\
\hline & & & LTS6 & 0.850 \\
\hline & & & LTS7 & 0.832 \\
\hline & & & LTS8 & 0.802 \\
\hline \multirow[t]{8}{*}{ Liderazgo transformacional } & \multirow[t]{8}{*}{0.729} & \multirow[t]{8}{*}{0.000} & LTF1 & 0.982 \\
\hline & & & LTF2 & 0.545 \\
\hline & & & LTF3 & 0.938 \\
\hline & & & LTF4 & 0.887 \\
\hline & & & LTF5 & 0.977 \\
\hline & & & LTF6 & 0.979 \\
\hline & & & LTF7 & 0.521 \\
\hline & & & LTF8 & 0.514 \\
\hline \multirow{4}{*}{$\begin{array}{l}\text { Compromiso org. con la } \\
\text { sustentabilidad }\end{array}$} & \multirow[t]{4}{*}{0.622} & \multirow[t]{4}{*}{0.000} & CS1 & 0.890 \\
\hline & & & $\mathrm{CS} 2$ & 0.892 \\
\hline & & & $\mathrm{CS} 3$ & 0.915 \\
\hline & & & CS4 & 0.872 \\
\hline \multirow[t]{9}{*}{ Competitividad } & \multirow[t]{9}{*}{0.871} & \multirow[t]{9}{*}{0.000} & $\mathrm{C} 1$ & 0.511 \\
\hline & & & $\mathrm{C} 2$ & 0.941 \\
\hline & & & $\mathrm{C} 3$ & 0.764 \\
\hline & & & $\mathrm{C} 4$ & 0.876 \\
\hline & & & $\mathrm{C} 5$ & 0.900 \\
\hline & & & C6 & 0.874 \\
\hline & & & $\mathrm{C} 7$ & 0.922 \\
\hline & & & $\mathrm{C} 8$ & 0.894 \\
\hline & & & C9 & 0.883 \\
\hline
\end{tabular}




\begin{tabular}{lll}
\hline Competitividad & $\mathrm{C} 10$ & 0.879 \\
$\mathrm{C} 11$ & 0.885 \\
$\mathrm{C} 12$ & 0.572 \\
$\mathrm{C} 13$ & 0.907 \\
\hline
\end{tabular}

Fuente: Elaboración propia

Para este estudio se aceptaron las cargas factoriales con valores superiores a 0.6 (Moriano, Topa, Valero y Lévy, 2009). Bajo este análisis se eliminaron los indicadores FO9, LTF2, LTF7, LTF8, C1 y C12, el resto de los indicadores se consideran aceptables y significativos al $95 \%$.

\section{Análisis de Fiabilidad del Constructo}

Para evaluar la fiabilidad del constructo se debe tener en cuenta la consistencia interna, la que exige que el Alpha de Cronbach sea mayor a 0.7 (Forcael, Vargas, Opazo y Medina, 2013). Junto a lo anterior, se realiza el cálculo de la fiabilidad compuesta (IFC) la cual tiene en cuenta las interrelaciones de los constructos; y tiene como valor mínimo 0.7 (Vila, Küster y Aldás, 2010). Los resultados indican que existe una consistencia interna de cada uno de los ítems que componen los constructos (Tabla $\underline{5}$ ).

\section{Validez convergente y discriminante}

Para continuar es necesario evaluar la validez de las escalas utilizadas (validez convergente), para lo cual se analiza la varianza extraída media (AVE). Se recomienda que esta sea superior a 0.5 con lo que se establece que más del $50 \%$ de la varianza del constructo se debe a sus indicadores (Forcael, Vargas, Opazo y Medina, 2013). Se observó que los constructos entregan un AVE superior a 0.5, por lo que se comprueba la validez convergente de éstos (Tabla 5). 
Ricardo Cabana Villca et al. / Contaduría y Administración 65(2) 2020 1-39

http://dx.doi.org/10.22201/fca.24488410e.2020.2007

Tabla 5

Fiabilidad del Constructo y Validez convergente. Indicadores Alpha de Cronbach, IFC y AVE

\begin{tabular}{llll}
\hline \multicolumn{1}{c}{ Constructo } & Alfa de Cronbach & IFC & AVE \\
\hline Factores organizacionales & 0.961 & 0.966 & 0.723 \\
Factores del entorno & 0.969 & 0.973 & 0.724 \\
Gerencia sustentable & 0.958 & 0.968 & 0.860 \\
Liderazgo transaccional & 0.927 & 0.941 & 0.663 \\
Liderazgo transformacional & 0.949 & 0.956 & 0.784 \\
Compromiso org. con la sustentabilidad & 0.913 & 0.939 & 0.793 \\
Competitividad & 0.975 & 0.940 & 0.786 \\
\hline
\end{tabular}

Fuente: Elaboración propia.

Finalmente, la validez discriminante indica en qué medida un constructo es diferente a los otros que conforman el modelo. Para comprobar este criterio de validación, se debe demostrar que las correlaciones entre los constructos son más bajas que la raíz cuadrada de la varianza extraída media AVE (Forcael, Vargas, Opazo y Medina, 2013). Como se observa en la Tabla 6 todos los valores cumplen para la validez discriminante.

Tabla 6

Validez discriminante

\begin{tabular}{llllllll}
\hline Constructo & C & CS & FE & FO & GS & LTS & LTF \\
\hline Competitividad (C) & 0.887 & & & & & &
\end{tabular}

\begin{tabular}{lcccccccc}
$\begin{array}{l}\text { Compromiso org. con la sustenta- } \\
\text { bilidad (CS) }\end{array}$ & 0.845 & 0.890 & & & & & \\
Factores del entorno (FE) & 0.830 & 0.860 & 0.850 & & & & \\
& & & & & & & & \\
& & & & & & & \\
Factores organizacionales (FO) & 0.851 & 0.865 & 0.767 & 0.851 & & & \\
Gerencia sustentable (GS) & 0.827 & 0.795 & 0.734 & 0.794 & 0.927 & & \\
Liderazgo transaccional (LTS) & 0.595 & 0.692 & 0.754 & 0.794 & 0.641 & 0.814 & \\
Liderazgo transformacional (LTF) & 0.816 & 0.829 & 0.756 & 0.843 & 0.870 & 0.717 & 0.885 \\
\hline
\end{tabular}

Fuente: Elaboración propia. 


\section{Resultados}

\section{Metodología para el modelo de Ecuaciones Estructurales}

Posteriormente a realizar el análisis factorial exploratorio y confirmatorio del modelo propuesto, se procede a utilizar las ecuaciones estructurales, a través del Método de Mínimos Cuadrados Parciales (PLS).

\section{Análisis de Relaciones Causales y Contraste de Hipótesis}

Los resultados que se muestran en la Tabla 7 indican la existencia de relaciones causales significativas entregadas por el coeficiente estandarizado y por el ratio crítico ( $t$-value) de los constructos superior a 1.96, por lo que se aceptan las 8 hipótesis planteadas en un comienzo. Los resultados de este análisis se grafican en la figura 2.

\section{Tabla 7}

Contraste de hipótesis del estudio

\begin{tabular}{lllll}
\hline $\begin{array}{l}\text { Signo de la } \\
\text { Hipótesis }\end{array}$ & Relación Estructural (Hipótesis) & $\begin{array}{l}\text { Paths } \\
(\beta)\end{array}$ & $\begin{array}{l}\text { Valor t (t-value) } \\
(\text { Bootstrap) }\end{array}$ & Contraste \\
\hline $\mathrm{H} 1+$ & Factores organizacionales $\rightarrow$ Compromiso org. S. & 0.551 & $9.445^{*}$ & Acepta \\
$\mathrm{H} 2+$ & Factores del entorno $\rightarrow$ Compromiso org. S. & 0.428 & $7.450^{*}$ & Acepta \\
$\mathrm{H} 3+$ & $\begin{array}{l}\text { Compromiso org. S. } \rightarrow \text { Liderazgo } \\
\text { transaccional }\end{array}$ & 0.931 & $136.443^{*}$ & Acepta \\
$\mathrm{H} 4+$ & $\begin{array}{l}\text { Compromiso org. S. } \rightarrow \text { Liderazgo } \\
\text { transformacional }\end{array}$ & 0.697 & $12.447^{*}$ & Acepta \\
$\mathrm{H} 5+$ & $\begin{array}{l}\text { Liderazgo transaccional } \rightarrow \text { Gerencia } \\
\text { sustentable }\end{array}$ & 0.424 & $4.698^{*}$ & Acepta \\
$\mathrm{H} 6+$ & Compromiso org. S. $\rightarrow$ Gerencia sustentable & 0.589 & $8.612^{*}$ & Acepta \\
$\mathrm{H} 7+$ & $\begin{array}{l}\text { Liderazgo transformacional } \rightarrow \text { Gerencia susten- } \\
\text { table }\end{array}$ & 0.127 & $3.090^{*}$ & Acepta \\
Gerencia sustentable $\rightarrow$ Competitividad + & & 0.827 & $40.495^{*}$ & Acepta \\
\hline
\end{tabular}

Fuente: Elaboración propia. 


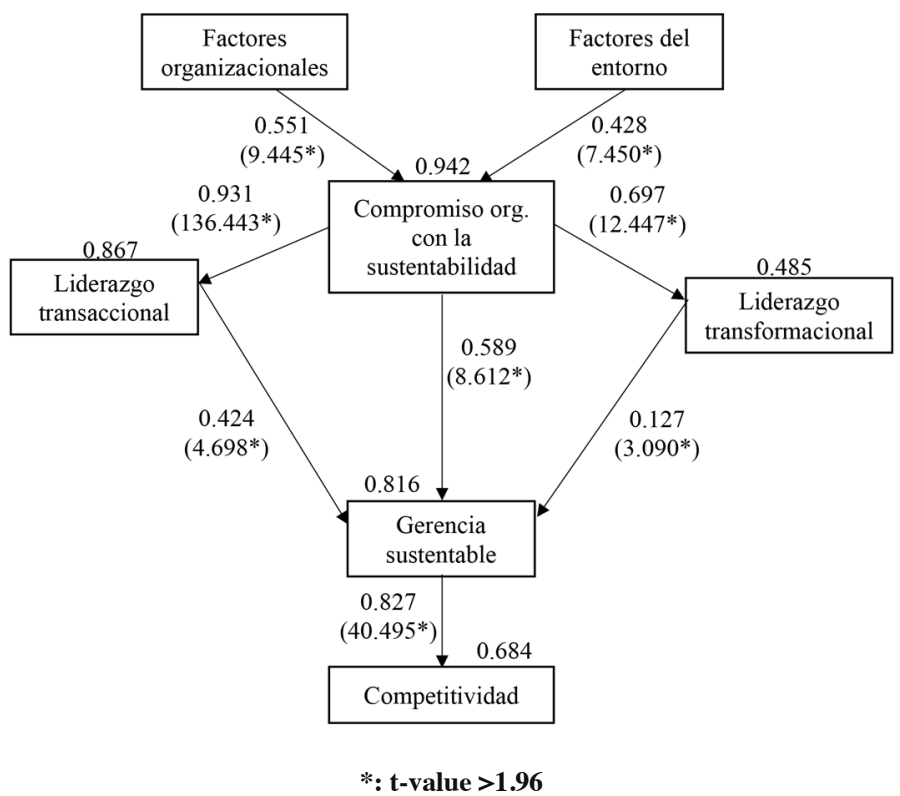

Figura 2. Modelo estructural gerencia sustentable.

Fuente: Elaboración propia.

\section{Validación del modelo estructural y Bondad de ajuste del modelo}

Se evalúan las relaciones causales que se proponen en el modelo, por medio de dos índices básicos: la varianza explicada de las variables dependientes $\left(\mathrm{R}^{2}\right)$ la cual debe ser superior a 0.33 para que se considere moderado (Johnson, Hermann y Huber, 2006). Por otra parte, la prueba que determina la calidad de predicción del modelo estructural es el Test de Stone-Geis$\operatorname{ser}\left(\mathrm{Q}^{2}\right)$. Este test se usa como criterio para medir la relevancia predictiva de los constructos dependientes y se calcula por medio de la técnica Blindfolding. En el caso de que la $\mathrm{Q}^{2}>0$, indica que el modelo tiene relevancia predictiva, en caso contrario, no la tiene (Chin, 1998). Como se aprecia en la Tabla 8 , todos los constructos cumplen con esta regla. 
Tabla 8

Validez del Modelo

\begin{tabular}{lll}
\hline Constructo & $\mathrm{R}^{2}$ & $\mathrm{Q}^{2}$ \\
\hline Compromiso org. con la sustentabilidad & 0.942 & 0.700 \\
Liderazgo transaccional & 0.867 & 0.528 \\
Liderazgo transformacional & 0.485 & 0.349 \\
Gerencia sustentable & 0.816 & 0.652 \\
Competitividad & 0.684 & 0.492 \\
\hline
\end{tabular}

Fuente: Elaboración propia.

Complementariamente, el índice de bondad de ajuste global (GOF), es el más apropiado al realizar el método PLS (Esposito, Chin, Henseler y Wang, 2010). El GOF del modelo de análisis es de 0,768 (Tabla 9); Lo cual demuestra que se tiene un buen ajuste en el modelo estructural, cumpliendo así con el criterio empírico de que la medida de bondad de ajuste debe variar entre 0 y 1, a mayor valor, mejor será el índice (Tenenhaus, 2008).

Tabla 9

Calculo de GOF

\begin{tabular}{lll}
\hline Constructo & AVE & $\mathrm{R}^{2}$ \\
\hline Gerencia sustentable & 0.860 & 0.816 \\
Liderazgo transaccional & 0.663 & 0.867 \\
Liderazgo transformacional & 0.784 & 0.485 \\
Compromiso org. con la sustentabilidad & 0.793 & 0.942 \\
Competitividad & 0.786 & 0.684 \\
Promedio & 0.777 & 0.759 \\
Raíz cuadrada & 0.882 & 0.871 \\
GOF & & 0.768 \\
\hline
\end{tabular}

Fuente: Elaboración propia. 


\section{Discusión}

El primer aporte relevante de esta investigación, es que se ratifica con confiabilidad estadística que la gerencia sustentable en las empresas del retail en la Región de Coquimbo, Chile, se genera a través de la gestión sistémica de 3 variables; compromiso organizacional con la sustentabilidad, liderazgo transaccional, liderazgo transformacional, variables que explican en un $81.6 \%$ la varianza de la gerencia sustentable que se instala en una organización, y ésta a su vez explica en un $68.4 \%$ la varianza de la competitividad.

La varianza del compromiso organizacional con la sustentabilidad es explicada en un 94.2\%, por los factores dcel entorno y los factores organizacionales, lo que es un nivel significativo según Moriano et al. (2009). El compromiso organizacional con la sustentabilidad presenta influencia estadística significativa y confirma su influencia positiva, sobre la generación y/o instalación de una gerencia sustentable, impactando en ese mismo sentido en la competitividad de la empresa. Por lo tanto, los líderes de las empresas del retail deben implementar programas para comunicar y potenciar efectiva y constantemente el marco estratégico, los valores y políticas organizacionales (Factores organizacionales). Los factores del entorno, tales como el empoderamiento de la comunidad, políticas de gobierno y desafíos de la industria, tienen significancia estadística e influyen de manera positiva sobre el compromiso con la sustentabilidad. Esto implica que las empresas del retail para instalar una gerencia sustentable, deben ser conocedoras de cuáles son las exigencias y las expectativas de sus clientes, a su vez deben alinearse con las políticas públicas de su país y contar con capacidades para superar los desafíos que presenta la industria donde participa, dadas las tendencias de la globalización. Así la empresa estará preparada para tomar decisiones que disminuyan los riesgos estratégicos y operacionales, creando además valor compartido que se debe distribuir equitativamente con todos sus stakeholders.

Respecto a la influencia individual de los constructos sobre la gerencia sustentable. El compromiso organizacional con la sustentabilidad tiene un mayor impacto positivo en la gerencia sustentable, seguido por el liderazgo transaccional y el liderazgo transformacional, pues presentan un coeficiente estandarizado de $0.589,0.424$ y 0.127 , respectivamente. Por lo tanto, para disponer de gerencia sustentable en las empresas del retail, sus líderes deben instalar una arquitectura organizacional que posibilite el logro de resultados crecientes, asignando recompensas equitativas, y además debe centrarse en desarrollar el potencial de su fuerza laboral y tomar decisiones que permitan paulatinamente la autorrealización. 


\section{Conclusion}

La competitividad de los retails requiere de incentivar la competitividad en sus proveedores, desarrollando clústers que potencien su cadena de valor, generando un menor impacto ambiental, creando un mejor acceso a conocimientos especializados, instalando un liderazgo basado en valores y de cumplimiento de metas, que permitirán construir una cultura organizacional donde la sustentabilidad sea el pilar del accionar de todos los trabajadores, alineándose integralmente a la fuerza laboral de sus mandantes. Así la gerencia sustentable, potenciará activos intangibles como; el valor de la marca, diferenciación y margen de ganancia competitivo, variables que le dan competitividad a las empresas del retail.

La competitividad de una empresa y la salud de los stakeholders donde opera, están fuertemente entrelazadas, de allí que es imprescindible la creación de valor compartido, pues la filantropía es insuficiente y el foco de las estrategias deben considerar su bienestar proactivamente, aunque esto aún no sea una demanda del marco legal o de las políticas corporativas existentes.

Clientes y sociedad deben actuar alineados a valores ambientales y sociales para producir empresas sustentables, las gerencias deben promover el consumo responsable de sus productos, aunque esto pueda implicar en el corto plazo, menores ingresos, pues así se potenciará el compromiso organizacional con la sustentabilidad, el desarrollo de esto requiere más acciones reales asociadas al "green marketing" y a la creación de valor compartido.

Los líderes y jefaturas de las empresas del retail, no sólo deben saber escuchar al cliente para innovar, sino que además deben escuchar, comprender y ser sensible a su entorno, y con ese capital relacional influir en el diseño de la empresa, para incrementar el compromiso, y como consecuencia se consolidará la grencia sustentable.

Una gerencia sustentable requiere que se contruya un compromiso organizacional con la sustentabilidad, un mayor vínculo relacional y sensibilidad con el entorno, que finalmente se expresa y/o visibiliza en el diseño y ejecución de la arquitectura organizacional de la empresa. Además, los directivos deben construir una arquitectura organizacional y/o ambiente laboral que estimule prácticas laborales sustentables, lo que será un reflejo del compromiso organizacional con la sustentabilidad, y así sentarán las bases para iniciar una gerencia sustentable. De esta forma la gerencia sustentable logrará que el gobierno corporativo y sus líderes trabajen alineados a la economía del bien común, asumiendo el desafío de incrementar el valor económico de la empresa, con responsabilidad social y ambiental, integrando esas tres prioridades en el modelo de negocios, de forma balanceada y pertinente, a la realidad de la empresa y los desafíos de su industria. 
Finalmente, el rol del estado es de suma importancia, pues no sólo deberá diseñar un marco regulatorio para el desarrollo del medio ambiente y la sociedad, sino que, además, deberán crear politicas públicas de sustentabilidad, para incentivar a las empresas privadas a ser constantes creadoras de valor compartido, un atributo relevante de la gerencia sustentable.

\section{Referencias}

Araque, D. L. J., Estepa, J. M. S., \& Uribe, A. F. (2017). Relación entre marketing interno y compromiso organizacional en Centros de Desarrollo Tecnológico colombianos. Estudios Gerenciales, 33(142), 95-101. https:// doi.org/10.1016/j.estger.2016.12.005

Arredondo, F. G. T., De la Garza, J. G., \& Parra, J. C. V. (2014). Transparencia en las organizaciones, una aproximación desde la perspectiva de los colaboradores. Estudios gerenciales, 30(133), 408-418. https://doi. org/10.1016/j.estger.2014.06.007

Ávila Foucat, V. S. (2017). Desafíos del sector primario y políticas públicas sustentables. Economía Informa, 402 , 29-39. https://doi.org/10.1016/j.ecin.2017.01.003

Botero, E. A. C., Acevedo, D. M. G., \& Gómez, J. M. S. (2013). La competitividad financiera: un componente fundamental de la competitividad empresarial. Contexto, 2(1), 136-150. Disponible en: http://revistas.ugca. edu.co/index.php/contexto/article/view/47. Consultado 12/04/2017.

Cabana, S. R., Cortés, F., Vega, D. L., \& Cornejo, J. (2016). Modelo de negocio: análisis en empresas del sector construcción, región Coquimbo-Chile. Ingeniería Industrial, 37(3), 298-304. Disponible en: http://scielo.sld. cu/scielo.php?script=sci_arttext\&pid=S1815-59362016000300008. Consultado 18/06/2017.

Cabana, S. R., Cortés, F. H., Vega, D. L., \& Cortés, R. A. (2016). Análisis de la Fidelización del Estudiante de Ingeniería con su Centro de Educación Superior: Desafíos de Gestión Educacional. Formación Universitaria, 9(6), 93-104. https://doi.org/10.4067/s0718-50062016000600009

Carro-Suárez, J., Sarmiento-Paredes, S., \& Rosano-Ortega, G. (2017). La cultura organizacional y su influencia en la sustentabilidad empresarial. La importancia de la cultura en la sustentabilidad empresarial. Estudios gerenciales, 33(145), 352-365. https://doi.org/10.1016/j.estger.2017.11.006

Castelao, M. E. C. (2016). Las políticas públicas y su visión de la economía social y solidaria en Argentina. Revista Mexicana de Ciencias Políticas y Sociales, 61(227), 349-378. https://doi.org/10.1016/S0185-1918(16)30032-0

Cencosud, (2016). Memoria anual Cencosud 2016. Disponible en: http://www.svs.cl/institucional/mercados/entidad.php?mercado. Consultado 21/04/2017.

Contreras, O. E., \& Rozo, I. R. (2015). Teletrabajo y sostenibilidad empresarial. Una reflexión desde la gerencia del talento humano en Colombia. Suma de Negocios, 6(13), 74-83. https://doi.org/10.1016/j.sumneg.2015.08.006

Corrêa, C. R. (2011). Cenários prospectivos e aprendizado organizacional em planejamento estratégico: estudo de casos de grandes organizações brasileiras (Doctoral dissertation, Tese (Doutorado). Rio do Janeiro: Instituto de Pós-Graduação e Pesquisa em Administração da Universidade Federal do Rio de Janeiro, COPPEAD/ UFRJ. Disponible en: http://www. coppead. ufrj. br/upload/publicacoes/Tese_Claudio_Correa. pdf. Consultado 13/03/2017.

Chen, C. C., Lee, C. C. y Lee, W. I. (2015). The relationship between internal marketing orientation, employee commitment, charismatic leadership and performance. International Journal of Organizational Innovation, 8(2), 67-78. https://doi.org/10.1145/2781562.2781563

Chin, W., (1998). The Partial Least Squares Approach to Structural Equation Modeling. Modern Methods for Business Research. Pp. 295-336. Mahwah, NJ: Lawrence Erlbaum Associates, Publisher. Disponible en: https:// www.researchgate.net/publication/311766005_The_Partial_Least_Squares_Approach_to_Structural_Equation_Modeling. Consultado: 15/04/2017 
De Mello, M. F. (2015). La importancia del liderazgo sostenible como una estrategia de las organizaciones. Revista Ciencias Estratégicas, 23(34), 209. http://dx.doi.org/10.18566/rces.v23n34.a4.

Delgado, M., Pedraja Rejas, L. \& Rodríguez Ponce, E. (2010). Estilos de Liderazgo y gestión de conocimiento en pequeñas empresas. Técnica Administrativa, 9(1) 1-13. Disponible en: http://www.cyta.com.ar/ta0901/v9n1a4. htm. Consultado: 15/04/2017

Díaz Cáceres, N. (2013). De la Sostenibilidad al Valor Compartido: Gerencia Estratégica de los Grupos de Interés. Daena: International Journal of Good Conscience, 8(1), 159-176. Disponible en: http://spentamexico. org/v8-n1/A13.8(1)159-176.pdf. Consultado: 19/04/2017

Duran, M. G. G., \& Castañeda, D. I. Z. (2015). Relación entre liderazgo transformacional y transaccional con la conducta de compartir conocimiento en dos empresas de servicios. Acta Colombiana de Psicología, 18(1), 135147. http://www.dx.doi.org/10.14718/ACP.2015.18.1.13

Economía y negocios, (2015). Retail mueve en torno a US\$ 76.000 millones en 2014. Disponible en: http://www. economiaynegocios.cl/noticias/noticias.asp?id=138812. Consultado: $22 / 04 / 2017$

Espinoza, M., Sanhueza, O., Ramírez, N., \& Sáez, K. (2015). A validation of the construct and reliability of an emotional intelligence scale applied to nursing students. Revista Latino-Americana de Enfermagem, 23(1), 139-147. http://dx.doi.org/10.1590/0104-1169.3498.2535

Esposito, V., Chin W., Henseler J. y Wang H. (2010). Handbook of Partial LeastSquares: Concepts, Methods and Applications 1st edition, Berlin: Springer-Verlag Berlin Heidelberg. https://doi.org/10.1007/978-3-540-32827-8

Falabella, (2016). Memoria anual Falabella 2016. Disponible en: http://www.svs.cl/institucional/mercados/entidad. php?mercado. Consultado: 19/02/2017

Febles A. J., \& Oreja R. J. (2008). Factores externos e internos determinantes de la orientación de la cultura estratégica de las empresas. Investigaciones Europeas de Dirección y Economía de la Empresa, 14(1), 13-32. https://doi.org/10.1016/S1135-2523(12)60009-4

Ferdig, M. A. (2009). Sustainability leadership relational model and practices. Omaha, NE: Sustainability Leadership Institute. Accessed June, 15, 2015. Disponible en: http://www.sustainabilityleadershipinstitute.org/atomic.php. Consultado: 25/04/2017

Forcael, E., Vargas, S., Opazo, A., \& Medina, L. (2013). Rol del ingeniero civil en la sociedad chilena contemporánea. Revista de La Construcción, 12(2), 72-87. http://dx.doi.org/10.4067/S0718-915X2013000200006

Fundación PROhumana, PNUD Chile (2002). Los chilenos Opinan: Responsabilidad Social de las Empresas. Análisis de la encuesta MORI sobre Responsabilidad Social Corporativa. Santiago, Chile: Ediciones PROhumana. Abril-2002. Disponible en: http://prohumana.cl/documentos/documentoafrica2002.pdf. Consultado: $21 / 02 / 2017$

Fred, D. (2017). Conceptos de administración estratégica. Boletín Científico de las Ciencias Económico Administrativas del ICEA, 5(9). https://doi.org/10.29057/icea.v5i9.2096

Gallardo, D. V. (2006). El Compromiso Con El Desarrollo Sostenible: Principios De Ecuador. Cuadernos de Economía, 25(45), 205-222. http://dx.doi.org/10.15446/cuad.econ.

García, J. J. O., Lara, J. D. D. L., \& de la Parra, J. P. N. (2017). Propuesta de un modelo de medición de la competitividad mediante análisis factorial. Contaduría y Administración. https://doi.org/10.1016/j. cya.2017.04.003

Hargreaves, A., \& Fink, D. (2007). 7 principios de un liderazgo sostenible. Padres y Maestros/Journal of Parents and Teachers, (310), 17-21. Disponible en: http://revistas.upcomillas.es/index.php/padresymaestros/article/ view/1659/2597. Consultado: 26/04/2017

Hermosilla, D., Amutio, A., da Costa, S., \& Páez, D. (2016). El Liderazgo transformacional en las organizaciones: variables mediadoras y consecuencias a largo plazo. Revista de Psicología del Trabajo y de las Organizaciones, 32(3), 135-143. http://dx.doi.org/10.1016/j.rpto.2016.06.003

Hernández, A., Ortega, D., \& Garzón, M. (2011). Diseño de un sistema de gestión estratégica para la Alcaldía Local del Sur-Oriente del distrito de Barranquilla. Dimensión. empresarial, 9(1), 41-54. Disponible en: https://www. researchgate.net/publication/256484594. Consultado: 27/04/2017 
Ibarra, M. J. P., Soto, K. J. G. \& Delgado, P.Z. Z. (2015). El liderazgo para la sustentabilidad; Un acercamiento nuevo a la forma de dirigir una organización. Catedra de contabilidad y sustentabilidad. Disponible en http://www. cumex.org.mx/index.php/catedras/index.php/catedras/index.php?option=com_content\&view=article\&layout=edit\&id=284\%22. Consultado: 28/04/2017

INE, (2016). Series mensuales desde enero de 2014 a la fecha. Disponible en: http://nuevoportal.ine.cl/estadisticas/ economicas/comercio?categoria. Consultado: 05/03/2017

Johnson, M., Hermann, A., \& Huber, F. (2006) The Evolution of Loyalty Intentions. http://dx.doi.org/10.1509/ jmkg.70.2.122

Matteo, C. A. (2014). Gerencia y Desarrollo Sustentable: un enfoque de ética y responsabilidad social. CLIC: Conocimiento Libre y Licenciamiento, (8). Disponible en: http://convite.cenditel.gob.ve/files/2015/01/ArticuloRevistaCLIC_n8_4.pdf. Consultado: 08/05/2017

Mendoza, A. I. M., García, B. R. R. y Xochitototl, V. N. (2014). Modelamiento estructural del compromiso organizacional, liderazgo transformacional y variables de resultado en personal que labora en escuelas públicas de educación básica en el distrito federal, Mexico. Disponible en: http://congreso.investiga.fca.unam.mx/docs/ xix/docs/3.08.pdf. Consultado: 12/05/2017

Moriano, J. A., Topa, G., Valero, E., \& Lévy, J. P. (2009). Identificación organizacional y conducta "intraemprendedora". Anales de Psicologia, 25(2), 277-287. Disponible en: https://digitum.um.es/xmlui/ bitstream/10201/14440/1/moriano.pdf. Consultado: 14/05/2017

Nelson, J. (2011). Corporate sustainability leadership at the edge. university of cambridge, programme for sustainable leadership. cambridge uk. Disponible en: https://sites.hks.harvard.edu/m-rcbg/CSRI/CPSL_ the_edge_Jane_Nelson.pdf.Consultado: 10/04/2017

Ortega, M. J. R., Villaverde, P. M. G., Moreno, J. J. J., \& Requena, G. P. (2008). Diferenciación en marketing y resultado de la empresa: análisis contingente y configuracional. Esic market, (129), 67-124. Disponible en: https://www.esic.edu/documentos/revistas/esicmk/080114_144404_E.pdf. Consultado: 10/04/2017

Peláez-León, J. D., Solarte, M. G., \& Rodríguez, A. R. A. (2014). La relación estratégica entre gestión humana y la responsabilidad social empresarial: Avances de una explicación en un caso colombiano. Suma de Negocios, 5(11), 15-28. https://doi.org/10.1016/S2215-910X(14)70016-3

Ramos, V. I., \& Maya, J. I. (2014). Sentido de comunidad, empoderamiento psicológico y participación ciudadana en trabajadores de organizaciones culturales. Psychosocial Intervention, 23(3), 169-176. http:// dx.doi.org/10.1016/j.psi.2014.04.001

Rivas Pardo, P. (2013). América Latina Tendencias y perspectivas del nuevo siglo. Ángel Soto y María Ignacia Matus (comps.). Estudios internacionales (Santiago), 45(175), 141-146. https://doi.org/10.5354/07193769.2013 .27386

Sánchez, P. V, (2011). Empresas sustentables, ¿cómo entenderlas? Disponible en: https://www.guioteca.com/rse/ empresas-sustentables-como-entenderlas/. Consultado: 27/04/2017

Sarmiento del Valle, S. (2010). Gestión estratégica: clave para la responsabilidad social de las empresas. Dimensión empresarial, 8(2), 24-37. Disponible en: https://www.researchgate.net/publication/277265517. Consultado: 28/04/2017

Silva Peralta, Y., Olsen, C., Pezzi, L., \& Sanjurjo, N. (2016). Liderazgo transaccional y transformacional de voluntarios jóvenes y adultos de Mar del Plata. Psicoperspectivas, 15(3), 146-157. http://dx.doi.org/10.5027/psicoperspectivas-Vol15-Issue3-fulltext-769. Consultado: 28/04/2017

SMU, (2016). Memoria anual SMU 2016. Disponible en: http://www.svs.cl/institucional/mercados/entidad. php?mercado. Consultado: 19/02/2017

Tenenhaus, M. (2008). Component-based structural equation modelling. Total Quality Management \& Business Excellence, 19, 871-886. http://dx.doi.org/10.1080/14783360802159543

Thompson, A., Peteraf, M., Gamble, J. \& Strickland, J. (2012). Administración estratégica. México: McGRAWHILL Interamericana Editores S.A. Consultado: 19/03/2017 
Varela, F. (2012). Liderazgo en el Sector Público. Aproximaciones y Desencuentros con el Sector Privado. Administración Pública, Universidad de Santiago de Chile. Consultado: 21/03/2017

Velásquez V., P. (2017). Desarrollo sustentable y la gerencia en Venezuela. Contextualizaciones latinoamericanas, número 16, enero-junio. Disponible en: http://www.revistascientificas.udg.mx/index.php/CL/article/ view/6903/5918. . Consultado: 03/04/2017

Vera Martínez, J. (2008). Perfil de valor de marca y la medición de sus componentes. Academia. Revista Latinoamericana de Administración, (41). Disponible en: http://www.redalyc.org/pdf/716/71611842007. Consultado: 15/04/2017

Vidal Ledo, M. J., \& Sánchez, A. M. P. (2016). Formación en Valores. Conceptos éticos y tecnológicos, métodos y estrategias. Infodir (Revista de Información para la Dirección en Salud), 10(18), 81-94. Disponible en: http:// scielo.sld.cu/scielo.php?script=sci_arttext\&pid=S0864-21412016000400016. Consultado: 19/03/2017

Vila, N., Küster, I., \& Aldás-Manzano, J. (2010). Desarrollo y validación de escalas de medida en Marketing. Análisis de Datos Multivariable, 1-22. Disponible en: https://www.researchgate.net/publication/267725602. Consultado: 02/04/2017

Walmart, (2016). Memoria anual Walmart Chile 2016. Disponible en: http://www.svs.cl/institucional/mercados/ entidad.php?mercado. Consultado: 19/02/2017

\section{Anexo \\ ENCUESTA \\ Encuesta sobre Gerencia Sustentable y su impacto en las empresas del Retail (Supermercados)}

El objetivo de esta encuesta es identificar las variables que provocan la existencia de gerencia sustentable (jefaturas cuyas decisiones consideren relevante el factor ambiental) y además evaluar los impactos que se generan en beneficio de la empresa, los clientes, los trabajadores y otros grupos de interés relevantes.

Instrucciones Generales:

- Seleccione la opción que considere más adecuada.

- Responda todas las preguntas lo más cuidadosamente posible.

1. Individualización del funcionario.

1.1 Género: Masculino

Femenino

1.2 Rango de edad:

18-25 años $26-35$ años $\quad 36-45$ años $\quad 46-56$ años $\quad 56$ años o más


1.3 Cargo en la Organización:

\begin{tabular}{|c|c|c|c|}
\hline Gerente & Administrador & Subadministrado & Supervisor \\
\hline Jefe de área & \multicolumn{3}{|l|}{ Personal de apoyo } \\
\hline \multicolumn{4}{|c|}{ 1.4 Antigüedad en la Organización: } \\
\hline Menos de 1 año. & \multicolumn{2}{|c|}{ Entre 6 y 10 años. } & e 16 y 20 años. \\
\hline Entre 1 y 5 años. & \multicolumn{2}{|c|}{ Entre 11 y 15 años. } & de 20 años. \\
\hline \multicolumn{4}{|l|}{ 1.5 Escolaridad } \\
\hline $\begin{array}{l}\text { Enseñanza media } \\
\text { completa }\end{array}$ & $\begin{array}{l}\text { Educación técnica } \\
\text { incompleta }\end{array}$ & $\begin{array}{l}\text { Eduación universitaria } \\
\text { incompleta }\end{array}$ & $\begin{array}{l}\text { Profesional titulado } \\
\text { tecnico }\end{array}$ \\
\hline $\begin{array}{l}\text { Profesional titulad } \\
\text { universitario }\end{array}$ & & & \\
\hline
\end{tabular}

2. Tamaño de la empresa

\begin{tabular}{lll}
$\begin{array}{l}\text { Empresa pequeña (1-50 } \\
\text { trabajadores) }\end{array}$ & Empresa mediana (51- & Empresa grande (más de \\
200 trabajadores) & 201 trabajadores) \\
\hline
\end{tabular}

3. Por favor indique el grado de acuerdo, con respecto a las siguientes afirmaciones sobre los factores organizacionales de su empresa, que afectan al compromiso de la organización con la sustentabilidad

\begin{tabular}{lllll}
\hline 1. Marco estratégico & $\begin{array}{l}\text { Totalmente en } \\
\text { desacuerdo }\end{array}$ & En desacuerdo & $\begin{array}{l}\text { Ni de acuerdo ni } \\
\text { en desacuerdo }\end{array}$ & $\begin{array}{l}\text { De acuerdo } \\
\text { mente de } \\
\text { acuerdo }\end{array}$ \\
\hline
\end{tabular}

1.1 En mi empresa todos los trabajadores somos conocedores de la misión y visión de la organización.

1.2 La empresa define su Visión, Misión y objetivos alineado/consistente al desarrollo sustentable de la sociedad y el bienestar de sus clientes.

1.3 La empresa cuenta con una estrategia para contribuir equitativamente a sus colaboradores externos (proveedores, comunidad, etc.), enfrentar los desafios de la sustentabilidad y la inequidad social. 
1.4 Las labores que desempeño en mi organización están alineadas/ consistente a los objetivos planteados en la misión y visión de mi empresa.

\section{Valores}

$\begin{array}{lllll}\begin{array}{l}\text { Totalmente en } \\ \text { desacuerdo }\end{array} & \text { En desacuerdo } & \begin{array}{l}\text { Ni de acuerdo ni } \\ \text { en desacuerdo }\end{array} & \begin{array}{l}\text { De } \\ \text { acuerdo }\end{array} & \begin{array}{l}\text { Totalmente } \\ \text { de acuerdo }\end{array}\end{array}$

2.1 En mi empresa se han definido claramente y son conocidos cuáles son los valores que guían nuestro accionar.

2.2 En mi empresa los valores nos guían para actuar y tomar decisiones que consideren el bienestar de mi organización y de los grupos de interés (proveedores, clientes, trabajadores, comunidad, etc.).

2.3 Los valores de mi organización establecen e incentivan expresamente a desarrollar formas adecuadas de relacionarse con el medio ambiente.

2.4 Los valores identifican el compromiso con el medioambiente, la satisfacción de los clientes y su personal.

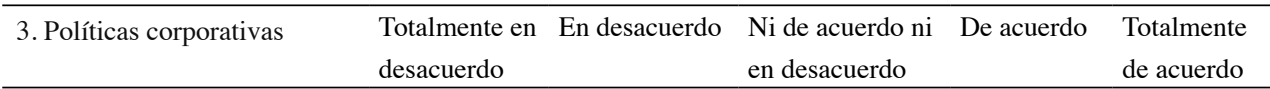

3.1 En mi empresa se promueve la existencia de un clima laboral sano, participativo, transparente, respetuoso, equitativo y comunicativo.

3.2 En mi empresa se promueve la conformación de sindicatos o formas de organización de los trabajadores, para así mejorar la calidad de vida y el dialogo entre las partes. 
3.3 En mi empresa existe una política de selección y contratación de personal que priori$\mathrm{za}$ a las personas que poseen valores ambientales y respeto por el entorno.

3.4 En mi empresa se ha elaborado una política ambiental que nos motiva a actuar con responsabilidad social y medio ambiental.

4. Por favor indique el grado de acuerdo, con respecto a las siguientes afirmaciones sobre los factores del entorno, que afectan al compromiso de su organización con la sustentabilidad

\begin{tabular}{llllll}
\hline $\begin{array}{l}\text { 4. Empoderamiento de la } \\
\text { comunidad }\end{array}$ & $\begin{array}{l}\text { Totalmente en } \\
\text { desacuerdo }\end{array}$ & $\begin{array}{ll}\text { En desacuer- } \\
\text { do }\end{array}$ & $\begin{array}{l}\text { Ni de acuerdo ni } \\
\text { en desacuerdo }\end{array}$ & De acuerdo & $\begin{array}{l}\text { Totalmente de } \\
\text { acuerdo }\end{array}$
\end{tabular}

4.1 En mi empresa se han establecido mecanismos de atención a los consumidores y comunidad en general, orientados a recoger sus reclamos y sugerencias, respecto a nuestro comportamiento ambiental.

4.2 En mi empresa existen y se ejecutan mecanismos para solucionar los conflictos de interés con la comunidad.

4.3 Mi empresa está en constante interés por identificar cuáles son los nuevos requerimientos de la comunidad, respecto a la protección del medio ambiente y la sustentabilidad.

4.4 En mi empresa se realizan inversiones e incentivos a la comunidad, para fortalecer las relaciones y el trabajo colaborativo. 
4.5 En mi empresa existen y se ejecutan mecanismos para hacer seguimiento y evaluación del impacto ambiental que provocamos con la operación y distribución de nuestros productos y servicios.

\begin{tabular}{|c|c|c|c|c|c|}
\hline 5. Políticas de gobierno & $\begin{array}{l}\text { Totalmente en } \\
\text { desacuerdo }\end{array}$ & En desacuerdo & $\begin{array}{l}\text { Ni de acuerdo ni } \\
\text { en desacuerdo }\end{array}$ & De acuerdo & $\begin{array}{l}\text { Totalmente } \\
\text { de acuerdo }\end{array}$ \\
\hline
\end{tabular}

5.1 En mi empresa se preocupan de cumplir la legislación chilena vigente respecto a los posibles impactos ambientales negativos.

5.2 En mi empresa se preocupan de cumplir la legislación chilena respecto a la vinculación con las comunidades.

$5.3 \mathrm{La}$ empresa conoce las normas ambientales que la controlan y establece los procedimientos y procesos para cumplirlas.

5.4 Las políticas de gobierno estimulan el desarrollo sustentable de la actividad económica de la empresa.

\begin{tabular}{lllll}
\hline Tendencias de la globalización & $\begin{array}{l}\text { Totalmente en } \\
\text { desacuerdo }\end{array}$ & En desacuerdo & $\begin{array}{l}\text { Ni de acuerdo ni } \\
\text { en desacuerdo }\end{array}$ & De acuerdo
\end{tabular}$\quad \begin{aligned} & \text { Totalmente } \\
& \text { de acuerdo }\end{aligned}$

6.1 Las empresas del sector (donde su empresa participa) se preocupan por instalar estrategias de sustentabilidad en su modelo de negocio para satisfacer nuevas expectativas ambientales de sus públicos de interés. 
6.2 La empresa está informada y preparada para el impacto que tienen los cambios políticos nacionales en relación con el medio ambiente y la sustentabilidad.

6.3 Las empresas del sector destinan fondos para la inversión en investigación y desarrollo de productos y servicios amigables con el medio ambiente.

6.4 La empresa toma en consideración las presiones o demandas sociales de la comunidad en el ámbito ambiental para realizar la oferta de sus productos y servicios.

6.5 La empresa se preocupa por la promoción del desarrollo tecnológico, que consolide un sello verde para así lograr generar una ventaja competitiva en su sector.

5. Por favor indique el grado de acuerdo, con respecto a las siguientes afirmaciones sobre los aspectos que generan compromiso con la sustentabilidad en su organización

\begin{tabular}{llllll}
\hline $\begin{array}{l}\text { Compromiso organizacional } \\
\text { con la sustentabilidad }\end{array}$ & $\begin{array}{l}\text { Totalmente en } \\
\text { desacuerdo }\end{array}$ & En desacuerdo & $\begin{array}{l}\text { Ni de acuerdo ni } \\
\text { en desacuerdo }\end{array}$ & $\begin{array}{l}\text { De } \\
\text { acuerdo }\end{array}$ & $\begin{array}{l}\text { Totalmente } \\
\text { de acuerdo }\end{array}$ \\
\hline 7.1 Los directivos de mi empre- & & & \\
sa se preocupa por expresar su & & & \\
satisfacción cuando los traba- & & & \\
jadores alcanzamos las metas & & & \\
ambientales propuestas. & & &
\end{tabular}


7.2 Mi empresa promueve en sus trabajadores un paradigma ecológico, con el fin de contribuir al desarrollo del intorno y entorno, y generar así un clima laboral que contribuye a mi fidelidad con los valores ambientales de la empresa y mejorar además mi desempeño.

7.3 Mi empresa no solo se preocupa por lograr rentabilidad económica, sino que además por lograr que todos sus públicos de interés (comunidad, cliente, trabajadores, proveedores, etc.) se comprometan con sus valores ambientales.

7.4 En mi empresa existe un sistema de recompensas equitativo que nos incentiva a aumentar nuestra productividad, alineados con una conducta ambiental.

6. Por favor indique el grado de acuerdo, con respecto a las siguientes afirmaciones sobre los atributos del gerente sustentable (jefaturas cuyas decisiones consideren relevante el factor ambiental) de su organización

\begin{tabular}{lllll}
\hline Gerencia Sustentable & $\begin{array}{l}\text { Totalmente en } \\
\text { desacuerdo }\end{array}$ & En desacuerdo & $\begin{array}{l}\text { Ni de acuerdo } \\
\text { ni en des- } \\
\text { acuerdo }\end{array}$ & De acuerdo \\
& & $\begin{array}{l}\text { Totalmente } \\
\text { de acuerdo }\end{array}$ \\
\hline
\end{tabular}

8.1 En mi empresa se promueve la generación de redes de cooperación estables, orientadas a provocar desarrollo ambiental, económico y social de las comunidades locales. 
8.2 En mi empresa se fomenta la competitividad sustentable de los proveedores (independiente del tamaño), con el fin de incluirlas en nuestra cadena de valor (operaciones y servicios internos), para fomentar nuestros resultados sustentables

8.3 En mi empresa se han establecido relaciones Trisectoriales (empresa, comunidad y estado) en post de resolver las distintas demandas ambientales de los públicos de interés (comunidad, cliente, trabajadores, proveedores, etc.).

8.4 En mi empresa se han diseñado e implementado proyectos de inclusión, inversión social con la comunidad, que impulsan el valor económico y ambiental de las empresas y de dichos colaboradores.

8.5 Se logran aumentos de productividad a nivel de la empresa, resolviendo problemas sociales y medioambientales que limitan la calidad y ecoeficiencia de sus operaciones.

\begin{tabular}{|c|c|c|c|c|c|}
\hline 9. Liderazgo transaccional & $\begin{array}{l}\text { Totalmente en } \\
\text { desacuerdo }\end{array}$ & En desacuerdo & $\begin{array}{l}\text { Ni de acuerdo ni } \\
\text { en desacuerdo }\end{array}$ & $\begin{array}{l}\text { De } \\
\text { acuerdo }\end{array}$ & $\begin{array}{l}\text { Totalmente } \\
\text { de acuerdo }\end{array}$ \\
\hline
\end{tabular}

9.1 Los líderes de la empresa se preocupan constantemente por disminuir la contaminación generada en la operación.

9.2 Los líderes de la empresa son eficientes en la toma de decisiones y ayudan con nuestro apoyo a disminuir los riegos ambientales y operacionales dentro de la organización.

9.3 Los líderes de la empresa se preocupan por optimizar el uso de energía para alcanzar una mayor rentabilidad. 
9.4 Los líderes en mi empresa impulsan a aumentar el valor de los productos y/o servicios disminuyendo el impacto ambiental que estos tienen y otorgando incentivos (tangibles o no) por sus logros.

9.5 Los líderes de la empresa se orientan a eliminar todas aquellas actividades que generen costos extras y no incrementan el valor ambiental de la empresa.

9.6 Los líderes en mi empresa han implementado procedimientos o tecnologías de eficiencia energética.

9.7 Los líderes en mi empresa han implementado medidas para disminuir y utilizar eficientemente el consumo de agua.

9.8 En mi empresa existen líderes que incentivan y fomentan el desarrollo de acciones cotidianas sustentables, para el bienestar de nosotros, los clientes y la sociedad.

10. Liderazgo transformacional Totalmente en En desacuerdo Ni de acuerdo ni De Totalmente desacuerdo en desacuerdo acuerdo de acuerdo

10.1 Los líderes de la empresa promueven la creación de valor dentro de la organización, incentivando una reinvención organizacional con conciencia ambiental, liderada por los mismos empleados. 
10.2 Los líderes de mi empresa saben dónde y cómo invertir para fidelizar y generar clientes socios pro medio ambiente (contribuyen con sus ideas para mejorar e innovar en nuestra empresa) y una ventaja competitiva adaptable al entorno.

10.3 Los líderes contagian a sus colaboradores los valores ambientales claves de la empresa, pues representan nuestro desarrollo y además el desarrollo sustentable de la organización.

10.4 Los líderes de la empresa estimulan a sus colaboradores a ser innovadores, creativos y a buscar por si mismos soluciones a problemas sociales $\mathrm{y}$ medioambientales.

10.5 Los líderes de la empresa toman en consideración las consecuencias ambientales y éticas que generan las decisiones que se implementen.

10.6 Los líderes de la empresa fomentan políticas de RRHH, que consolidan en nosotros una cultura de compromiso basada en valores para el cuidado del medio ambiente y el desarrollo de las comunidades.

10.7 Los líderes en mi empresa han implementado prácticas ambientales con los clientes interno. 
10.8 Los líderes en mi empresa han transferido buenas prácticas en materia de sustentabilidad a los proveedores y comunidad relevante para impulsar su desarrollo económico.

7. Por favor indique el grado de acuerdo, con respecto a las siguientes afirmaciones sobre los factores resultantes de la gerencia sustentable (jefaturas cuyas decisiones consideren relevante el factor ambiental) en su organización, que provocan y generan competitividad

\begin{tabular}{|c|c|c|c|c|c|}
\hline 11. Valor de la marca & $\begin{array}{l}\text { Totalmente en } \\
\text { desacuerdo }\end{array}$ & En desacuerdo & $\begin{array}{l}\text { Ni de acuerdo } \\
\text { ni en des- } \\
\text { acuerdo }\end{array}$ & $\begin{array}{l}\text { De } \\
\text { acuerdo }\end{array}$ & $\begin{array}{l}\text { Total- } \\
\text { mente de } \\
\text { acuerdo }\end{array}$ \\
\hline
\end{tabular}

11.1 La marca de mi empresa tiene una reputación medioambiental destacada, lo que contribuye con su liderazgo en el sector.

11.2 La marca de mi empresa se relaciona con un consumo y vida sustentable, lo que le da competitividad.

11.3 La marca de mi empresa, influye a que los clientes, proveedores y futuros trabajadores, nos prefieran como empresa para trabajar o relacionarse con nosotros.

11.4 La marca de mi empresa se relaciona con sustentabilidad corporativa y ambiental.

\begin{tabular}{|c|c|c|c|c|c|}
\hline $\begin{array}{l}\text { 12. Diferenciación } \\
\text { corporativa }\end{array}$ & $\begin{array}{l}\text { Totalmente en } \\
\text { desacuerdo }\end{array}$ & En desacuerdo & $\begin{array}{l}\text { Ni de acuer- } \\
\text { do ni en } \\
\text { desacuerdo }\end{array}$ & De acuerdo & $\begin{array}{l}\text { Totalmente de } \\
\text { acuerdo }\end{array}$ \\
\hline
\end{tabular}

12.1 La empresa se preocupa por ofrecer productos amigables con el medio ambiente. 
12.2 Los productos y servicios de mi empresa, innovan continuamente para entregar una propuesta de valor cuyo sello verde le da ventajas competitivas en el sector.

12.3 El marketing de la empresa, usa su compromiso ambiental, como factor de diferenciación con la competencia en el sector.

12.4 Los productos que se comercializan en esta empresa tienen la capacidad de mantenerse en el mercado pese a los cambios que este pueda tener.

12.5 Esta empresa tiene la capacidad de diferenciarse con su competencia, empleando como una oportunidad las exigencias ambientales.

\begin{tabular}{|c|c|c|c|c|c|}
\hline $\begin{array}{l}\text { 13. Margen de ganancia } \\
\text { competitiva }\end{array}$ & $\begin{array}{l}\text { Totalmente en } \\
\text { desacuerdo }\end{array}$ & En desacuerdo & $\begin{array}{l}\mathrm{Ni} \text { de acuerdo ni } \\
\text { en desacuerdo }\end{array}$ & $\begin{array}{l}\text { De } \\
\text { acuerdo }\end{array}$ & $\begin{array}{l}\text { Totalmente de } \\
\text { acuerdo }\end{array}$ \\
\hline
\end{tabular}

13.1 La tecnología y procesos amigables con el medio ambiente, contribuyen con lograr un margen de ganancia de la empresa y su crecimiento sobre sus competidores.

13.2 La sustentabilidad empresarial contribuye a mejorar los resultados económicos y financieros de mi empresa. 
13.3 Comercializar productos amigables con el medio ambiente, le da a mi empresa una demanda creciente y superior a sus competidores. 13.4 Mi empresa se preocupa por ser eficiente, mejorar la productividad, reducir costos en la realización de las actividades y contribuir a maximizar los resultados optimizando sustentablemente los recursos asignados.

13.5 Los resultados económicos y/o sus márgenes de ganancia de mi empresa mejoran al ejecutar acciones sustentables, estrategias asociativas $\mathrm{y} / \mathrm{o}$ inclusivas con los stakeholders (clientes, proveedores, trabajadores, comunidad, etc.). 